\title{
Nongenomic Glucocorticoid Inhibition via Endocannabinoid Release in the Hypothalamus: A Fast Feedback Mechanism
}

\author{
Shi Di, ${ }^{1}$ Renato Malcher-Lopes, ${ }^{2}$ Katalin Cs. Halmos, ${ }^{1}$ and Jeffrey G. Tasker ${ }^{1,2}$ \\ ${ }^{1}$ Division of Neurobiology, Department of Cell and Molecular Biology, and ${ }^{2}$ Neuroscience Program, Tulane University, New Orleans, Louisiana 70118-5698
}

Glucocorticoid negative feedback in the brain controls stress, feeding, and neural-immune interactions by regulating the hypothalamicpituitary-adrenal axis, but the mechanisms of inhibition of hypothalamic neurosecretory cells have never been elucidated. Using wholecell patch-clamp recordings in an acute hypothalamic slice preparation, we demonstrate a rapid suppression of excitatory glutamatergic synaptic inputs to parvocellular neurosecretory neurons of the hypothalamic paraventricular nucleus (PVN) by the glucocorticoids dexamethasone and corticosterone. The effect was maintained with dexamethasone conjugated to bovine serum albumin and was not seen with direct intracellular glucocorticoid perfusion via the patch pipette, suggesting actions at a membrane receptor. The presynaptic inhibition of glutamate release by glucocorticoids was blocked by postsynaptic inhibition of G-protein activity with intracellular GDP- $\beta$-S application, implicating a postsynaptic G-protein-coupled receptor and the release of a retrograde messenger. The glucocorticoid effect was not blocked by the nitric oxide synthesis antagonist $N^{\mathrm{G}}$-nitro-L-arginine methyl ester hydrochloride or by hemoglobin but was blocked completely by the $\mathrm{CB}_{1}$ cannabinoid receptor antagonists AM251 [N-(piperidin-1-yl)-5-(4-iodophenyl)-1-(2,4-dichlorophenyl)4-methyl-1H-pyrazole-3-carboxamide] and AM281 [1-(2,4-dichlorophenyl)-5-(4-iodophenyl)-4-methyl- $N$-4-morpholinyl-1H-pyrazole3-carboxamide] and mimicked and occluded by the cannabinoid receptor agonist WIN55,212-2 [( $\beta)-(+)-[2,3$-dihydro-5-methyl-3-(4morpholinylmethyl)pyrrolo[1,2,3-de]-1,4-benzoxazin-6-yl]-1-naphthalenylmethanone mesylate], indicating that it was mediated by retrograde endocannabinoid release. Several peptidergic subtypes of parvocellular neuron, identified by single-cell reverse transcriptonPCR analysis, were subject to rapid inhibitory glucocorticoid regulation, including corticotropin-releasing hormone-, thyrotropinreleasing hormone-, vasopressin-, and oxytocin-expressing neurons. Therefore, our findings reveal a mechanism of rapid glucocorticoid feedback inhibition of hypothalamic hormone secretion via endocannabinoid release in the PVN and provide a link between the actions of glucocorticoids and cannabinoids in the hypothalamus that regulate stress and energy homeostasis.

Key words: glucocorticoid; endocannabinoid; hypothalamus; retrograde messenger; parvocellular neuron; G-protein; membrane receptor; corticotropin-releasing hormone; thyrotropin-releasing hormone; vasopressin; oxytocin

\section{Introduction}

Glucocorticoids secreted by the adrenal cortex exert inhibitory effects on several hypothalamic neuroendocrine systems, including but not limited to the negative feedback regulation of the hypothalamic-pituitary-adrenal (HPA) axis by suppression of the secretion of corticotropin-releasing hormone (CRH) from neurons of the hypothalamic paraventricular nucleus (PVN) (Herman et al., 1996; de Kloet, 2000). The glucocorticoid negative feedback regulation of the HPA axis occurs acutely by a relatively rapid inhibition of $\mathrm{CRH}$ release and chronically by downregulating $\mathrm{CRH}$ and vasopressin (VP) expression in PVN neurons (Keller-Wood and Dallman, 1984). Classical glucocorticoid actions, like those of other steroid hormones, are mediated by binding to intracellular receptors and regulation of gene transcription (Falkenstein et al., 2000). Recent evidence in different species suggests that rapid glucocorticoid actions are mediated by membrane receptors and activation of nongenomic signaling

\footnotetext{
Received 0ct. 11, 2002; revised March 24, 2003; accepted March 25, 2003.

This work was supported by National Institutes of Health Grants NS/DK39099 and MH066958. We thank Harold Gainer, Eric Glasgow, and D. James Surmeier and his laboratory colleagues for their help in setting up the single-cell RT-PCR technique in our laboratory. We thank James Herman and F. Edward Dudek for their critical reading of this manuscript.

Correspondence should be addressed to Dr. Jeffrey G. Tasker, Department of Cell and Molecular Biology, 2000 Percival Stern Hall, Tulane University, New Orleans, LA 70118-5698. E-mail: tasker@tulane.edu.

Copyright $\odot 2003$ Society for Neuroscience $\quad$ 0270-6474/03/234850-08\$15.00/0
}

mechanisms. Thus, glucocorticoids have been shown to bind specifically to cellular membrane sites (Suyemitsu and Terayama, 1975; Harrison et al., 1979; Orchinik et al., 1991) and to induce rapid influences on electrolyte movement across cellular membranes (Avanzino et al., 1987; Hua and Chen, 1989; ffrench-Mullen, 1995). Although the molecular identity of the membrane-associated receptors for corticosteroids is still unresolved, a high-affinity binding site for corticosterone, which appears to meet all of the criteria for a functional membrane-associated corticosteroid receptor, has been partially purified and characterized in neuronal membranes from amphibian brain (Evans et al., 2000). However, it remains controversial where in the mammalian brain and through which mechanisms glucocorticoids mediate their rapid feedback regulation of the HPA axis. Here, we show that glucocorticoids exert a rapid inhibitory effect on glutamate release onto identified parvocellular neurons of the PVN, including CRH neurons, by activating a G-proteindependent signaling mechanism that leads to the retrograde release of an endocannabinoid and results in the suppression of synaptic glutamate release.

\section{Materials and Methods}

Slice preparation. Male Sprague Dawley rats (3-5 weeks of age; Charles River Laboratories, Wilmington, MA) were used in these experiments according to a protocol approved by the Tulane University Institutional Animal Care and Use Committee and in accordance with United States 
Public Health Service guidelines. Rats were deeply anesthetized with pentobarbital sodium $(50 \mathrm{mg} / \mathrm{kg}$ body weight) and decapitated. The brain was quickly removed from the cranial cavity after cutting the optic nerves and immersed in cooled $\left(1-2^{\circ} \mathrm{C}\right)$, oxygenated artificial CSF (aCSF). The composition of the aCSF was as follows (in $\mathrm{mm}$ ): $140 \mathrm{NaCl}, 3 \mathrm{KCl}, 1.3$ $\mathrm{MgSO}_{4}, 1.4 \mathrm{NaH}_{2} \mathrm{PO}_{4}, 2.4 \mathrm{CaCl}_{2}, 11$ glucose, and 5 HEPES, $\mathrm{pH}$ adjusted to $7.2-7.3$ with $\mathrm{NaOH}$. The hypothalamus was blocked and the caudal surface of the block was glued to the chuck of a vibrating microtome (World Precision Instruments, Sarasota, FL). Two coronal hypothalamic slices $(350 \mu \mathrm{m})$ containing the PVN were sectioned, bisected along the midline (i.e., at the third ventricle), and submerged in a holding chamber in oxygenated aCSF at room temperature, where they were allowed to equilibrate for $>1.5 \mathrm{hr}$ before being transferred to the recording chamber.

Electrophysiological methods. Patch pipettes were pulled from borosilicate glass (1.65 mm outer diameter, $1.2 \mathrm{~mm}$ inner diameter; KG33; Garner Glass, Claremont, CA) with a Flaming/Brown P-97 micropipette puller (Sutter Instruments, Novato, CA) to a resistance of 3-4 M $\Omega$. The pipette solution contained (in $\mathrm{mm}$ ): $120 \mathrm{~K}$-gluconate, $10 \mathrm{KCl}, 1 \mathrm{NaCl}, 1$ $\mathrm{MgCl}_{2}, 1$ EGTA, $2 \mathrm{Mg}$-ATP, $0.3 \mathrm{Na}-\mathrm{GTP}$, and 10 HEPES, $\mathrm{pH}$ adjusted to 7.3 with $\mathrm{KOH}$. The osmolarity of the solution was adjusted to $300 \mathrm{mOsm}$ with 20 mM D-sorbitol.

Hemislices were transferred one at a time from the holding chamber to a submersion recording chamber, secured to the floor of the chamber with $\mathrm{AgCl}_{2}$-coated wire, and allowed to equilibrate for at least $15 \mathrm{~min}$ before recordings. Medial PVN neurons were visualized with a cooled CCD camera using infrared illumination and differential interference contrast optics and patch-clamped under visual control. After achieving the whole-cell configuration, series resistance and whole-cell capacitance were adjusted and continuously monitored during experiments. Recordings with unstable series resistance were discarded. Whole-cell recordings were performed in voltage-clamp mode using an Axopatch 1-D amplifier (Axon Instruments, Foster City, CA) and monitored continuously on a digital storage oscilloscope (Hitachi, Tokyo, Japan). All data were low-pass-filtered at $2 \mathrm{kHz}$, converted to digital video format at 22 $\mathrm{kHz}$ using a Neuro-Corder (NeuroData Instruments, New York, NY), and stored on videotape for off-line analysis. Selected data were subsequently digitized off-line at $4 \mathrm{kHz}$ and recorded on a personal computer using the Digidata 1200 interface and pClamp 7.0 software (Axon Instruments). Miniature EPSCs (mEPSCs) in putative parvocellular PVN neurons were recorded in the presence of the voltage-gated sodium channel blocker tetrodotoxin (TTX) $(1 \mu \mathrm{M})$ at a holding potential of $-60 \mathrm{mV}$ at $22-24^{\circ} \mathrm{C}$. To focus on the fast, nongenomic actions of glucocorticoids, 3 min epochs of mEPSCs were collected just before bath application of glucocorticoids and after $7 \mathrm{~min}$ of glucocorticoid application. The frequency, amplitude, and decay time (defined as the time from peak to the point at which the mEPSC had decayed by $63 \%$ ) of mEPSCs were analyzed using the Minianalysis 5.0 program (Synaptosoft, Decatur, GA). Statistical analyses were performed using the Student's paired $t$ test for within-cell comparisons, the Student's unpaired $t$ test for between-group comparisons, and the Kolmogorov-Smirnov nonparametric test for within-cell comparisons of mEPSC distribution; $p$ values of $<0.05$ were considered significant.

Type II, putative parvocellular PVN neurons were differentiated from type I, putative magnocellular PVN neurons on the basis of their location in the PVN, morphology, and the absence of transient outward rectification (Hoffman et al., 1991; Tasker and Dudek, 1991; Luther et al., 2000). The presence of transient outward rectification was assessed with a current-clamp protocol consisting of a series of progressively more depolarizing current injections from a hyperpolarization to near $-100 \mathrm{mV}$. Transient outward rectification, found only in type I putative magnocellular neurons, was identified as a pronounced dampening of the membrane-charging curve that was associated with a delay in the onset of depolarization-induced action potentials. Type II neurons were divided into putative neurosecretory and non-neurosecretory parvocellular neurons on the basis of the expression or lack of expression of a calciumdependent low-threshold spike (Luther et al., 2002). Only putative parvocellular neurosecretory neurons, which lacked a low-threshold spike, were included in this study.
Drug application. Water-soluble forms of the steroids dexamethasone (DEX) $(0.01-100 \mu \mathrm{M})$, corticosterone $(1 \mu \mathrm{M})$, and cholesterol $(5 \mu \mathrm{M})$ (Sigma-Aldrich, St. Louis, MO) were directly dissolved in aCSF to final concentrations and applied in the bath perfusion. The DEX-bovine serum albumin (BSA) conjugate $(10 \mu \mathrm{M})$ (purified to remove free steroids by the supplier; Steraloids, Newport, RI) was dissolved in aCSF with $25 \%$ $\beta$-cyclodextrin (Sigma-Aldrich) as a carrier to increase its solubility. The concentration of DEX-BSA, $(10 \mu \mathrm{M})$ was selected to obtain an effective concentration of dexamethasone of $\sim 1 \mu \mathrm{M}$, because the BSA conjugation reduces the effectiveness of receptor binding by a factor of $\sim 10$. TTX (1 $\mu \mathrm{M})$ (Sigma-Aldrich), the nitric oxide (NO) synthase (NOS) inhibitor $N^{\mathrm{G}}$-nitro-L-arginine methyl ester hydrochloride (L-NAME) $(50 \mu \mathrm{M})$ (Tocris Cookson, Ellisville, $\mathrm{MO}$ ), and the carbon monoxide (CO)-NO scavenger hemoglobin ( $20 \mu \mathrm{M}$; Sigma-Aldrich) were dissolved in sterile water and stored in $10 \mathrm{~mm}$ stock solutions at $-20^{\circ} \mathrm{C}$. The physiologically inactive steroid isopregnanalone ( $5 \mu \mathrm{M})$, the intracellular type I and type II corticosteroid receptor antagonists spironolactone $(10 \mu \mathrm{M})$ and mifepristone (RU486) (10 $\mu \mathrm{M})$, the protein kinase blockers staurosporine (1 $\mu \mathrm{M})$ and bisindolylmaleimide (GF109203X) $(0.5 \mu \mathrm{M})$ (Sigma-Aldrich), the cannabinoid receptor agonist $(R)-(+)$-[2,3-dihydro-5-methyl-3(4-morpholinylmethy) pyrrolo[1,2,3-de]-1,4-benzoxazin-6-yl]-1-naphthalenylmethanone mesylate (WIN55,212-2) $(1 \mu \mathrm{M})$, and the cannabinoid receptor antagonists $N$-(piperidin-1-yl)-5-(4-iodophenyl)-1-(2,4-dichlorophenyl)-4-methyl-1H-pyrazole-3-carboxamide (AM251) (1 $\mu \mathrm{M}), 1-(2,4-$ dichlorophenyl)-5-(4-iodophenyl)-4-methyl- $N$-4-morpholinyl-1H-pyrazole-3-carboxamide (AM281) $(10 \mu \mathrm{M})$, and 6-iodo-2-methyl-1-[2(4-morpholinyl)ethyl]-1H-indol-3-yl] (AM630) (1-10 $\mu \mathrm{M})$ (Tocris Cookson) were stored as $10 \mathrm{~mm}$ stock solutions in DMSO at $-20^{\circ} \mathrm{C}$ and dissolved to their final concentrations in aCSF before bath application. The cannabinoid analogs were also dissolved with $25 \%$ $\beta$-cyclodextrin. The DMSO and $\beta$-cyclodextrin solutions without the cannabinoids or glucocorticoids had no effect on mEPSCs at the concentrations used. The nonhydrolyzable guanylyl nucleotide GDP- $\beta$-S $(500 \mu \mathrm{M})$ (Sigma-Aldrich) and, in some cases, dexamethasone $(1 \mu \mathrm{M})$ were included in the patch solution for intracellular application. To prevent drugs destined for intracellular application from leaking into the extracellular space before a membrane seal was obtained, the tips of the patch pipettes were filled first with regular patch solution and then back-filled with the drug solution.

Single-cell reverse transcription-PCR. The single-cell reverse transcription (RT)-PCR procedure was similar to that described by Surmeier et al. (1996), with minor modifications. The cell contents were aspirated into the patch pipette under visual control, taking care to avoid aspiration of the nucleus, and transferred into $5 \mu \mathrm{l}$ of a lysis buffer containing (in $\mu \mathrm{l}$ ) 2.9 of diethyl pyrocarbonate (DEPC)-treated water, 0.7 of BSA, 0.7 of oligo-dT $(0.5 \mu \mathrm{g} / \mu \mathrm{l})$, and 0.7 of RNasin $(40 \mathrm{U} / \mu \mathrm{l})$, which was maintained on ice before and after harvesting of the cytoplasm. The cells were stored at $-80^{\circ} \mathrm{C}$ or used immediately for RT. The lysate-buffer mixture was heated to $70^{\circ} \mathrm{C}$ for $10 \mathrm{~min}$ and incubated on ice for $1 \mathrm{~min}$, after which 15 $\mu \mathrm{l}$ of final RT master mix, containing (in $\mu \mathrm{l}$ ) 8.0 of DEPC-treated water, 2 of $10 \times$ first-strand buffer, 2 of $\mathrm{MgCl}_{2}(25 \mathrm{~mm}), 2$ of DTT ( $\left.0.1 \mathrm{M}\right)$, and 1 of mixed deoxy NTPs (dNTPs) (10 mm), was added. Single-stranded cDNA was reverse transcribed from the cellular mRNA by adding $0.7 \mu \mathrm{l}$ of SuperScript II reverse transcriptase $(200 \mathrm{U} / \mu \mathrm{l})$ and incubating at $42^{\circ} \mathrm{C}$ for $50 \mathrm{~min}$, after which the reaction was terminated by heating to $70^{\circ} \mathrm{C}$ for $15 \mathrm{~min}$. The RNA strand in the RNA-DNA hybrid was removed by adding $0.5 \mu \mathrm{l}$ of RNase $\mathrm{H}(2 \mathrm{U} / \mu \mathrm{l})$ for $20 \mathrm{~min}$ at $37^{\circ} \mathrm{C}$. All reagents were obtained from Invitrogen (Madison, WI).

PCR amplification was performed with a thermal cycler (MJ Research, Watertown, MA) using a fraction of the single-cell cDNA as a template. Reaction mixtures contained ( $30 \mu \mathrm{l}$ final volume): $2.2 \mathrm{mM} \mathrm{MgCl}_{2}$, a 0.5 mu concentration of each of the dNTPs, a $1.5 \mu \mathrm{M}$ concentration of primers, $2.5 \mathrm{U}$ of Taq DNA polymerase, $2.9 \mu \mathrm{l}$ of $10 \times$ buffer, and $4 \mu \mathrm{l}$ of the cDNA template made from the single-cell RT reaction. The thermal cycling program was set at $94^{\circ} \mathrm{C}$ for $45 \mathrm{sec}, 60^{\circ} \mathrm{C}$ for $45 \mathrm{sec}$, and $72^{\circ} \mathrm{C}$ for 1.10 min for 50 cycles.

Primers for $\mathrm{CRH}$ and thyrotropin-releasing hormone (TRH) were designed in our laboratory using Primer Select 4 (DNAStar, Madison, $\mathrm{WI}$ ), and primer designs for VP, oxytocin (OT) and glyceraldehyde-3- 
phosphate dehydrogenase (GAPDH) were taken from Glasgow et al. (1999). All primers were synthesized by Integrated DNA Technologies (Coralville, IA). The following primers were used: CRH, 5' -GCCCCGC AGCCGTTGAA-3' and 5'-GACCGCCTCCCTCTCTCCAG-3' (326 bp product); TRH, 5'-GGGGACCTCGGTGCTGCCTTAGAC-3' and 5'CTGCCGCTTGACTTGGGGGACATC-3' (276 bp); OT, 5'-GACGGT GGATCTCGGACTGAA-3' and 5'-CGCCCCTAAAGGTATCATC ACAAA-3' (462 bp); VP, 5' -CCTCACCTCTGCCTGCTACTT-3' and 5'-GGGGGCGATGGCTCAGTAGAC-3' (440 bp); GAPDH, 5'-GGAC ATTGTTGCCATCAACGAC-3' and 5'-ATGAGCCCTTCCACGAT GCCAAAG-3' (441 bp). Each of the primers was used for every cell analyzed. Final PCR products were visualized by staining with ethidium bromide after separation by electrophoresis in 1.5-2\% agarose gels. The forward and reverse GAPDH primers were designed to span an intron to detect genomic DNA in each cellular template. In addition to the singlecell GAPDH RT-PCR, whole hypothalamic slices were run in parallel with the single-cell reactions as positive controls for the primers. Negative controls for contamination from extraneous and genomic DNA were also run for every batch of neurons by running pure water or by omitting the RT step from the reaction, respectively. None of the cells tested showed a genomic DNA PCR product.

\section{Results}

To characterize the fast effects of glucocorticoids on putative neurosecretory parvocellular PVN neurons, we performed whole-cell patch-clamp recordings in neurons located in the medial parvocellular region of the PVN in acutely prepared hypothalamic slices. A total of 131 putative neurosecretory parvocellular PVN neurons, identified on the basis of their visualized position within the PVN and on electrophysiological criteria described in Materials and Methods, were recorded in acute hypothalamic slices from 80 rats. mEPSCs were recorded at a holding potential of $-60 \mathrm{mV}$, which was close to the calculated chloride equilibrium potential $\left(\mathrm{E}_{\mathrm{Cl}}=-63.3 \mathrm{mV}\right)$, in the presence of TTX $(1 \mu \mathrm{M})$. They were blocked by the glutamate receptor antagonists AP-5 $(50 \mu \mathrm{M})$ and DNQX $(30 \mu \mathrm{M})(n=4)$ but were not affected by the $\mathrm{GABA}_{\mathrm{A}}$ receptor antagonist bicuculline methiodide (30 $\mu \mathrm{M})(n=6)$, indicating that they were mediated by synaptically released glutamate. Data were collected after an initial $10 \mathrm{~min}$ baseline period was established during which the amplitude and frequency of mEPSCs were stable. The mEPSCs recorded under control conditions ranged in amplitude from 8.2 to $36.9 \mathrm{pA}$, in frequency from 0.34 to $6.95 \mathrm{~Hz}$, and in decay time from 1.8 to 4.5 msec.

\section{Glucocorticoids inhibit glutamate release}

The glucocorticoids dexamethasone and corticosterone applied in the bath perfusion had no effect on membrane-holding current or input conductance in any of the neurons tested but suppressed glutamatergic synaptic activity within 3-5 min in 22 of 25 putative parvocellular neurosecretory neurons of the PVN (i.e., $>10 \%$ change in mEPSC frequency). Dexamethasone $(1 \mu \mathrm{M})$, a selective synthetic glucocorticoid receptor agonist, caused a significant decrease in the frequency $(3.11 \pm 0.52$ to $1.83 \pm 0.39 \mathrm{~Hz}$; $58.8 \pm 4.8 \%$ of baseline; $p<0.01 ; n=18$ ), but not the amplitude $(24.77 \pm 1.95$ vs $24.10 \pm 1.76$ pA; $98.18 \pm 1.5 \%$ of baseline; $p=$ $0.13)$ or decay time $(3.52 \pm 0.17$ vs $3.68 \pm 0.16 \mathrm{msec} ; 105.0 \pm$ $4.5 \%$ of baseline; $p=0.32$ ) of mEPSCs (Fig. $1 a-c$ ). The inhibitory effect of dexamethasone on mEPSC frequency had a rapid onset (3-5 min) and was dose dependent, with a threshold concentration between 10 and $100 \mathrm{~nm}$ and a saturating concentration between 1 and $10 \mu \mathrm{M}$ (Fig. 1d). Corticosterone $(1 \mu \mathrm{M})$ had a similar inhibitory effect on mEPSCs, causing a decrease in the mEPSC frequency $(1.90 \pm 0.57$ to $1.39 \pm 0.43 \mathrm{~Hz} ; 72.4 \pm 4.6 \%$ of baseline; $p<0.01 ; n=7$ ) (Fig. $1 e$ ), without affecting either the a

Control

DEX
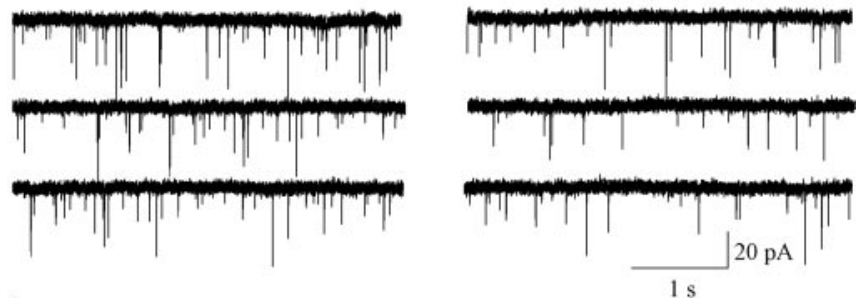

b
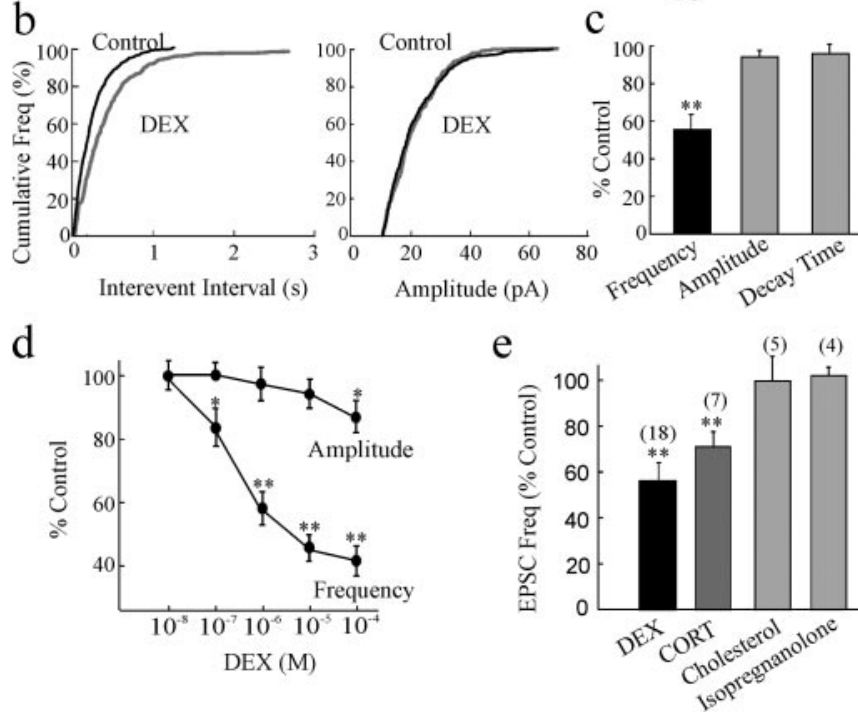

Figure 1. Glucocorticoids inhibited glutamate release onto PVN parvocellular neurons. $a$ Bath application of DEX (1 $\mu \mathrm{m})$ elicited a decrease in the frequency of mEPSCs. $b$, Cumulative frequency plots of $\mathrm{mEPSC}$ interval and amplitude distributions from the same cell showed a significant reduction in $\mathrm{mEPSC}$ frequency $(p<0.01)$ with no change in $\mathrm{mEPSC}$ amplitude $(p=0.28)$. $c$, Mean changes in the average mEPSC frequency, amplitude, and decay time in dexamethasone $(1 \mu \mathrm{m})$ in 18 PVN parvocellular neurons. $d$, The dexamethasone-induced decrease in $\mathrm{mEPSC}$ frequency was dose dependent. e, Corticosterone (CORT, $1 \mu \mathrm{M}$ ) caused a similar decrease in the mean frequency of mEPSCs, whereas the corticosteroid precursor cholesterol (5 $\mu \mathrm{M}$ ) and the physiologically inactive steroid isopregnanolone $(5 \mu \mathrm{m})$ had no effect on mEPSC frequency. Numbers in parentheses represent numbers of cells analyzed in each condition in this and in the following figures. ${ }^{*} p<0.05 ;{ }^{* *} p<0.01$.

mEPSC amplitude (33.16 \pm 0.14 vs $31.75 \pm 0.57 \mathrm{pA} ; 97.0 \pm 2.4 \%$ of baseline; $p=0.13$ ) or decay time $(4.06 \pm 0.85$ vs $3.79 \pm 0.76$ msec; $98.0 \pm 6.13 \%$ of baseline; $p=0.36$ ). The effect of glucocorticoid did not reverse after 60 min of washout of the steroid. The effect was steroid-specific, because the corticosteroid precursor cholesterol $(5 \mu \mathrm{M})$ and the physiologically inactive steroid isopregnanolone $(5 \mu \mathrm{M})$ had no effect on mEPSCs (Fig. 1e). Thus, glucocorticoids exerted a fast inhibitory effect on glutamate release onto PVN parvocellular neurons.

The glucocorticoid effect is mediated by a membrane receptor The rapid onset of the effect of glucocorticoid (3-5 $\mathrm{min}$ ) suggested a nongenomic mechanism of steroid action. We conducted a series of experiments to determine whether the effect of glucocorticoid on glutamate release was mediated by activation of the classical intracellular corticosteroid receptors. The decrease in mEPSC frequency induced by dexamethasone was not blocked by a previous $10 \mathrm{~min}$ bath application of the intracellular type I or type II corticosteroid receptor antagonists spironolactone $(10 \mu \mathrm{M})$ and mifepristone $(10 \mu \mathrm{M})$, respectively (Fig. $2 a)$. Additionally, dexamethasone $(1 \mu \mathrm{M})$ applied directly into the cytoplasm of parvocellular neurons by including it in the patch 


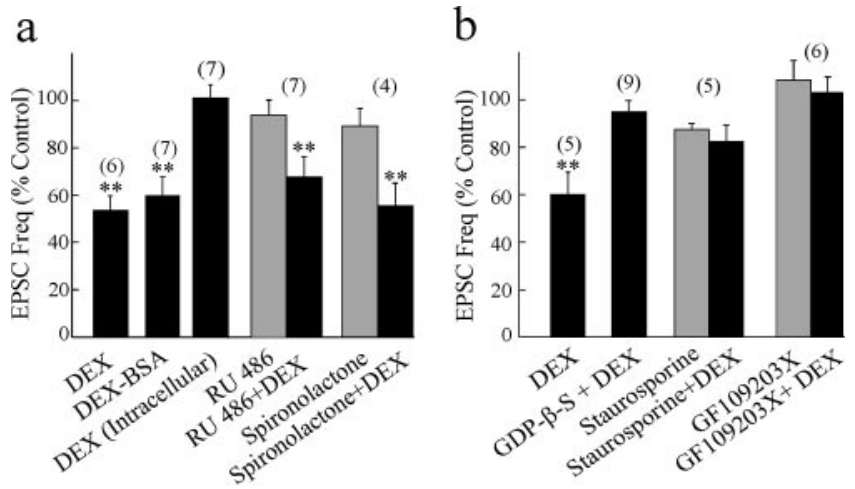

Figure 2. The glucocorticoid effect was mediated by a postsynaptic, G-protein-coupled membrane receptor. $a$, Bath application of membrane-impermeant DEX-BSA maintained the inhibitory effect, whereas intracellular application of dexamethasone (1 $\mu \mathrm{m})$ had no effect on the frequency of mEPSCs. The intracellular glucocorticoid receptor antagonist RU486 (10 $\mu \mathrm{m})$ and the intracellular mineralocorticoid receptor antagonist spironolactone (10 $\mu \mathrm{m})$ failed to block the inhibitory effect of dexamethasone on mEPSCs. b, G-protein and protein-kinase blockers abolished the effect of glucocorticoid on mEPSCs. Postsynaptic G-protein blockade with intracellular GDP- $\beta$-S application (500 $\mu \mathrm{m}$ ) blocked the effect of dexamethasone on mEPSC, implicating a postsynaptic G-protein-coupled mechanism. Kinase inhibition with bath application of staurosporine $(0.5 \mu \mathrm{m})$ or a PKC blocker, GF109203X (0.5 $\mu \mathrm{m})$, also abolished the inhibitory effect of dexamethasone on mEPSCs, suggesting a PKC-dependent mechanism that is either presynaptic or postsynaptic. ${ }^{* *} p<0.01$.

pipette had no effect on the frequency of mEPSCs (101.4 $\pm 4.5 \%$ of baseline after $10 \mathrm{~min}$ of recording; $n=7$ ) (Fig. $2 a$ ). Also, bath application of a membrane-impermeant DEX-BSA conjugate $(10 \mu \mathrm{M})$ retained the inhibitory effect of dexamethasone on mEPSC frequency $(2.18 \pm 0.77$ to $1.39 \pm 0.54 \mathrm{~Hz} ; 60.2 \pm 7.3 \%$; $p<0.01 ; n=7)$. These data indicated that the inhibitory effect of glucocorticoids on glutamate release was not mediated by the classical intracellular corticosteroid receptors, and suggested a mechanism involving a membrane-associated receptor.

\section{G-protein and protein-kinase dependence}

We investigated the molecular mechanisms of the rapid glucocorticoid effect in parvocellular neurons by testing for G-protein and protein-kinase dependence. The G-protein antagonist GDP- $\beta$-S $(500 \mu \mathrm{M})$ was applied intracellularly via the patch pipette to block postsynaptic G-protein activity in the PVN parvocellular neurons. Intracellular application of GDP- $\beta$-S (10 min) blocked the decrease in mEPSC frequency evoked by dexamethasone $(94.7 \pm 4.7 \%$ of baseline; $p=0.11 ; n=9)$ (Fig. $2 b)$. Because GDP- $\beta$-S is not membrane-permeant, this indicated that the effect of glucocorticoid on glutamate release was dependent on postsynaptic G-protein activity in the parvocellular neurons. To determine the protein-kinase dependence of the glucocorticoid effect, staurosporine, a broad-spectrum protein kinase inhibitor, and GF109203X, a protein kinase C (PKC)selective blocker, were applied in the bath $10 \mathrm{~min}$ before dexamethasone application. Staurosporine $(0.5 \mu \mathrm{M})$ attenuated the inhibitory effect of dexamethasone on mEPSC frequency to nonsignificant levels ( $82.5 \pm 6.9 \%$ of baseline; $p=0.25 ; n=5)$, and GF109203X $(0.5 \mu \mathrm{M})$ blocked the dexamethasone effect completely $(102.7 \pm 5.8 \%$ of baseline; $n=6$ ) (Fig. $2 b$ ). Thus, the inhibitory effect of glucocorticoids on glutamate release in PVN parvocellular neurons is dependent on kinase activity, although it is not yet known whether the kinase dependence of the action of glucocorticoid is presynaptic and/or postsynaptic.

\section{The glucocorticoid effect is mediated by a retrograde} endocannabinoid messenger

Our data show, on one hand, that glucocorticoids reduced glutamate release, indicating a presynaptic steroid effect, and on the other hand, that the effect of glucocorticoid was dependent on postsynaptic G-protein signaling, indicating a postsynaptic site of steroid action. This suggested that the actions of glucocorticoid are mediated by the release from PVN parvocellular neurons of a retrograde messenger that inhibits presynaptic glutamate release.

NOS is expressed at high levels in the PVN (Bredt et al., 1990) and has been proposed as an intranuclear messenger in the regulation of GABA inputs to PVN magnocellular neurons (Bains and Ferguson, 1997). We tested whether NO or CO functions as the retrograde messenger that modulates glutamate release in response to glucocorticoids. Bath application of L-NAME (50 $\mu \mathrm{M})$, a NOS inhibitor, failed to block the effect of dexamethasone $(1 \mu \mathrm{M})$ on mEPSC frequency (decrease to $68.4 \pm 6.7 \%$ of baseline; $p<0.05 ; n=5$ ) (Fig. $3 a-c$ ). Similarly, bath application of hemoglobin $(20 \mu \mathrm{M})$, the extracellular NO and CO scavenger, also failed to block the decrease in mEPSC frequency induced by dexamethasone $(1 \mu \mathrm{M}$ ) (to $72.3 \pm 10.7 \%$ of baseline; $p<0.05$; $n=6$ ) (Fig. $3 c$ ). Neither CO nor NO, therefore, appears to play a role in the response to glucocorticoids.

Endocannabinoids have been shown to act as retrograde messengers that reduce synaptic glutamate and GABA release (Shen et al., 1996; Auclair et al., 2000; Wilson and Nicoll, 2001; Wilson et al., 2001). We examined whether an endocannabinoid serves as the retrograde messenger in the rapid, glucocorticoid-mediated inhibition of glutamate release. Bath application of the type I cannabinoid receptor $\left(\mathrm{CB}_{1}\right)$ antagonists AM251 $(1 \mu \mathrm{M})$ and AM281 $(10 \mu \mathrm{M})$ blocked the dexamethasone-induced reduction in mEPSC frequency (AM251: $94.4 \pm 2.7 \%$ of AM251 value, or $87.0 \pm 4.9 \%$ of baseline, $p=0.20, n=7$; AM281: $99.7 \pm 4.2 \%$ of AM281 value, or $82.9 \pm 8.7 \%$ of baseline, $p=0.29, n=7$ ) (Fig. $4 a, b)$. The type II cannabinoid receptor $\left(\mathrm{CB}_{2}\right)$ antagonist AM630 failed to block the effect of dexamethasone on mEPSC frequency at a concentration selective for $\mathrm{CB}_{2}$ receptors ( $1 \mu \mathrm{M}$ : $71.0 \pm 9.6 \%$ of AM630 value or $69.5 \pm 11.3 \%$ of baseline; $p<0.05 ; n=5$ ) but blocked the dexamethasone effect at a higher, nonselective concentration ( $10 \mu \mathrm{M}$ : $101.9 \pm 9.1 \%$ of baseline; $n=6)$ (Fig. $4 c)$. The high-affinity synthetic cannabinoid agonist WIN55,212-2 mimicked and occluded the inhibitory effect of glucocorticoids on glutamate release. Thus, bath application of WIN55,212-2 (0.5 $1 \mu \mathrm{M})$ caused a significant decrease in mEPSC frequency $(70.3 \pm$ $6.9 \%$ of baseline; $p<0.01 ; n=13$ ) but had no effect on mEPSC amplitude $(101.1 \pm 3.4 \%)$ or decay time $(104.6 \pm 2.8 \%)$ (Fig. $4 d, e)$. Dexamethasone application $(1 \mu \mathrm{M})$ after $10 \mathrm{~min}$ of WIN55,212-2 application $(1 \mu \mathrm{M})$ failed to elicit any additional decrease in mEPSC frequency $(96.2 \pm 5.8 \%$ of the WIN55,212-2 value; $p=0.25 ; n=5$ ) (Fig. $4 f$ ). Therefore, the inhibitory effect of glucocorticoids on glutamate release appears to be mediated by a retrograde endocannabinoid messenger and activation of presynaptic $\mathrm{CB}_{1}$ receptors. Application of the cannabinoid antagonists AM281 $(10 \mu \mathrm{M})$ and AM630 $(10 \mu \mathrm{M})$ subsequent to dexamethasone application did not reverse the inhibitory effect of dexamethasone on glutamate release (data not shown), which suggested that the nonreversibility of the effect of glucocorticoid was caused by a mechanism downstream from the presynaptic cannabinoid receptors.

\section{Glucocorticoid effects on multiple parvocellular cell types}

Parvocellular PVN neurons tested for their sensitivity to glucocorticoids or cannabinoids were screened for CRH, TRH, OT, 
a

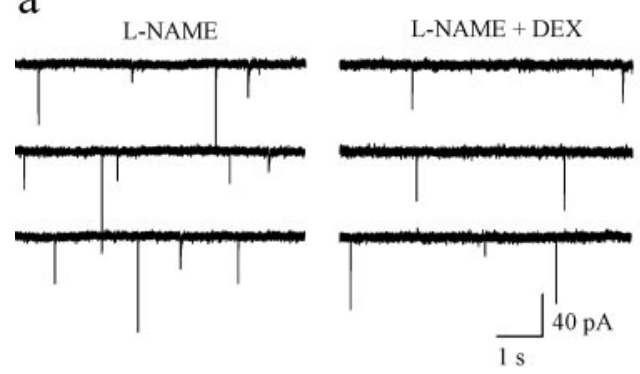

b

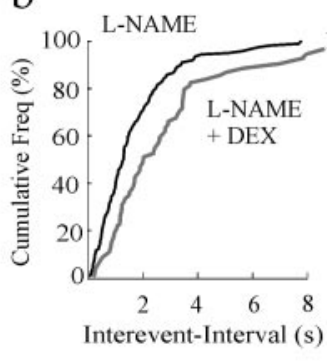

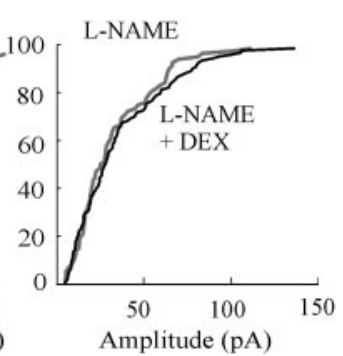

c

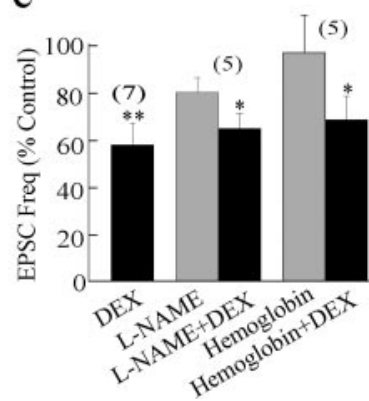

Figure 3. Glucocorticoid inhibition of glutamate release was not mediated by NO or CO $a$, The dexamethasone-induced suppression of mEPSCs was not blocked by the previous bath application of the NOS inhibitor L-NAME $(10 \mu \mathrm{M}) . b$, Cumulative frequency plots showed a significant reduction in mEPSC frequency $(p<0.05)$ with no change in mEPSC amplitude $(p=0.24)$ in the presence of L-NAME and DEX. c, The NO-CO scavenger hemoglobin $(10 \mu \mathrm{m})$ also failed to block the inhibitory effect of dexamethasone on the frequency of $\mathrm{mEPSCs} .{ }^{*} p<0.05$; ${ }^{* *} p<0.01$.

a

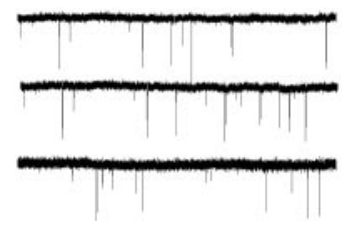

d

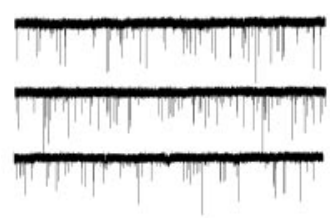

$\mathrm{AM} 251+\mathrm{DEX}$

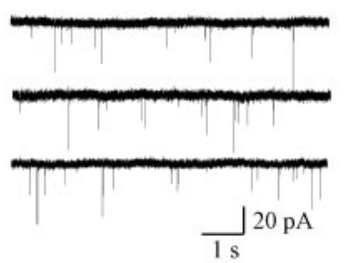

b

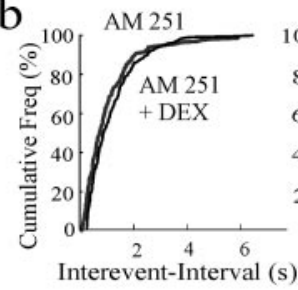

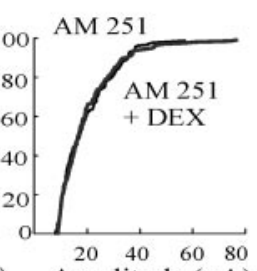

Amplitude (pA)

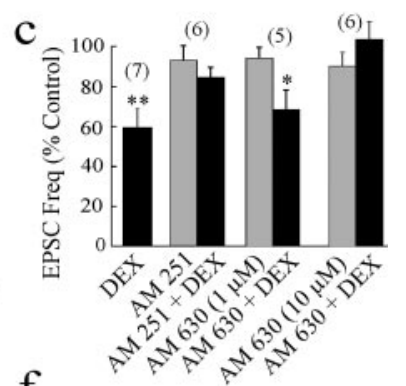

e

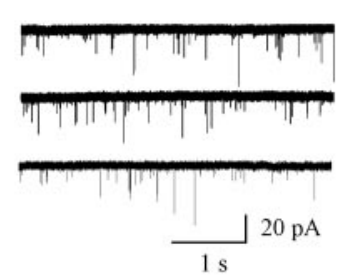

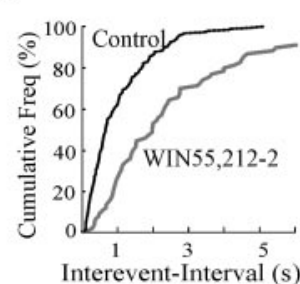

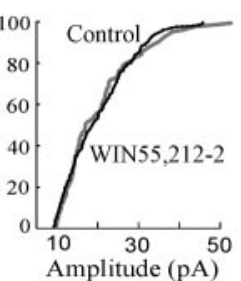

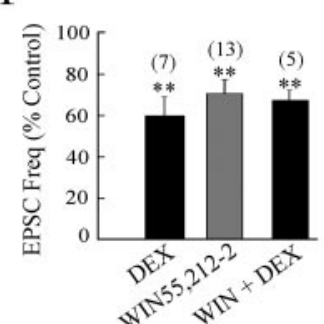

Figure 4. The effect of glucocorticoid on glutamate release was mediated by an endocannabinoid. $a$, The dexamethasone-induced suppression of mEPSCs was prevented by previous bath application of the $\mathrm{CB}_{1}$ receptor antagonist $\mathrm{AM} 251(1 \mu \mathrm{M})$. b. There was no effect of dexamethasone on the cumulative mEPSC interevent interval or amplitude distribution in the presence of AM251. $c$, Mean changes in average mEPSC frequency in the presence of cannabinoid receptor antagonists. The $C_{1}$ receptor antagonist AM251 blocked the effect of dexamethasone on mEPSC frequency. The $\mathrm{CB}_{2}$ receptor antagonist AM630 failed to block the DEX effect at a $1 \mu \mathrm{m}$ concentration but blocked the DEX effect at the higher, nonselective $10 \mu \mathrm{m}$ concentration. $d$, A cannabinoid receptor agonist, WIN55,212-2 (1 $\mu \mathrm{M})$, mimicked the glucocorticoid effect, causing a selective reduction in the frequency of mEPSCs. e, Cumulative frequency plots showed a significant increase in mEPSC interval ( $p<0.01$ ) but no change in mEPSC amplitude ( $p=0.42$ ) in WIN55,212-2.f, Mean changes in the average mEPSC frequency in the presence of glucocorticoid and the cannabinoid receptor agonist. The effect of WIN55,212-2 was similar to that of dexamethasone, but these effects were not additive, suggesting converging mechanisms. ${ }^{*} p<0.05$; ${ }^{* *} p<0.01$.

and VP mRNA expression using the single-cell RT-PCR technique after experiments (Surmeier et al., 1996; Glasgow et al., 1999). Of 30 neurons responsive to glucocorticoids, five expressed $\mathrm{CRH}$, two expressed TRH, four expressed OT, and three expressed VP mRNAs. Of 16 neurons responsive to cannabinoid analogs, one expressed $\mathrm{CRH}$, four expressed OT, and two expressed VP mRNAs. Each of the identified cells expressed only one of the four mRNAs (Fig. 5), except one cell in which expression of both TRH and OT was detected. These findings indicate that the glucocorticoid-induced suppression of glutamate synaptic inputs occurs in different peptidergic phenotypes among neurosecretory parvocellular PVN neurons, and suggest a generalized feedback inhibitory role of glucocorticoids in the regulation of hypophysiotropic hormone secretion.

\section{Discussion}

Together, our data demonstrate a fast, membrane corticosteroid receptor-mediated suppression of excitatory input to neurosecretory parvocellular neurons of the PVN, and support a model of acute glucocorticoid actions (Fig. 6). In this model, glucocorticoids activate a postsynaptic G-protein-coupled membrane receptor that leads to the release of an endocannabinoid. The endocannabinoid acts as a retrograde messenger at presynaptic glutamate terminals to inhibit glutamate release onto the parvocellular neurons, thereby decreasing the excitatory synaptic drive to these cells.

\section{A membrane G-protein-coupled glucocorticoid receptor}

Several findings presented here support the involvement of a membrane glucocorticoid receptor in the acute effects of corticosteroids on PVN parvocellular neurons: (1) the rapid response to extracellular corticosteroids, (2) the lack of effect of intracellular corticosteroid application, (3) the maintained effectiveness of the membrane-impermeant DEX-BSA conjugate, and (4) the failure of antagonists of the classical intracellular corticosteroid receptors to block the acute corticosteroid effect. Additionally, blockade of the corticosteroid effect by blocking G-protein activity selectively in the postsynaptic neuron implicates a G-protein- 
a

a
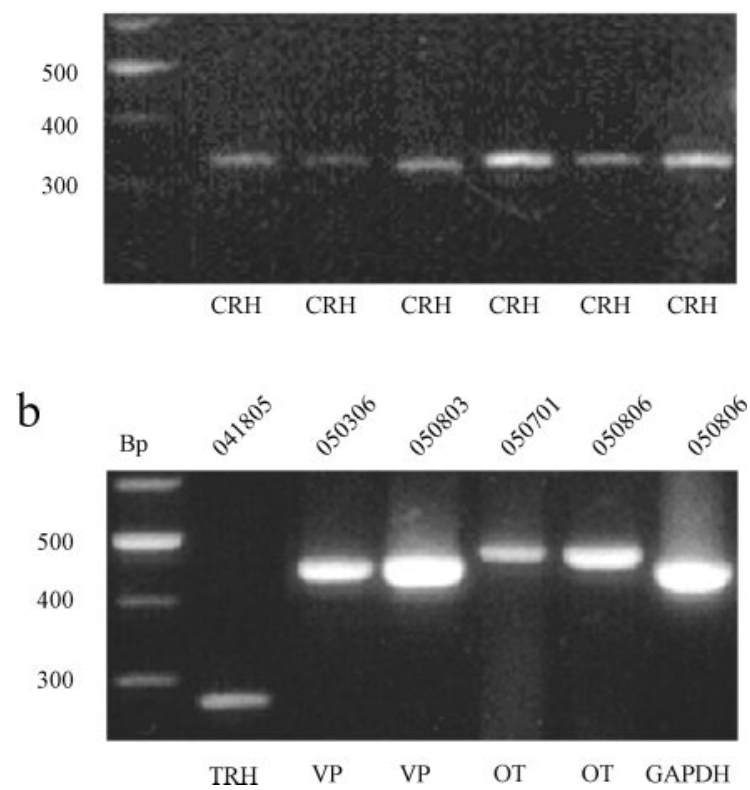

Figure 5. RT-PCRanalysis in individual parvocellular neurons. $a$, CRH mRNA expression in six individual PVN parvocellular neurons. The expected CRH PCR product is $326 \mathrm{bp} . b$, TRH, VP, OT, and GAPDH mRNA expression in individual PVN parvocellular neurons. The expected $P C R$ product weights are $276 \mathrm{bp}$ (TRH), $440 \mathrm{bp}$ (VP), $463 \mathrm{bp}$ (0T) and $441 \mathrm{bp}$ (GAPDH). The cell identification numbers are shown above each lane. A DNA ladder ranging from 300 to 500 bp is shown in the left lane of each panel.

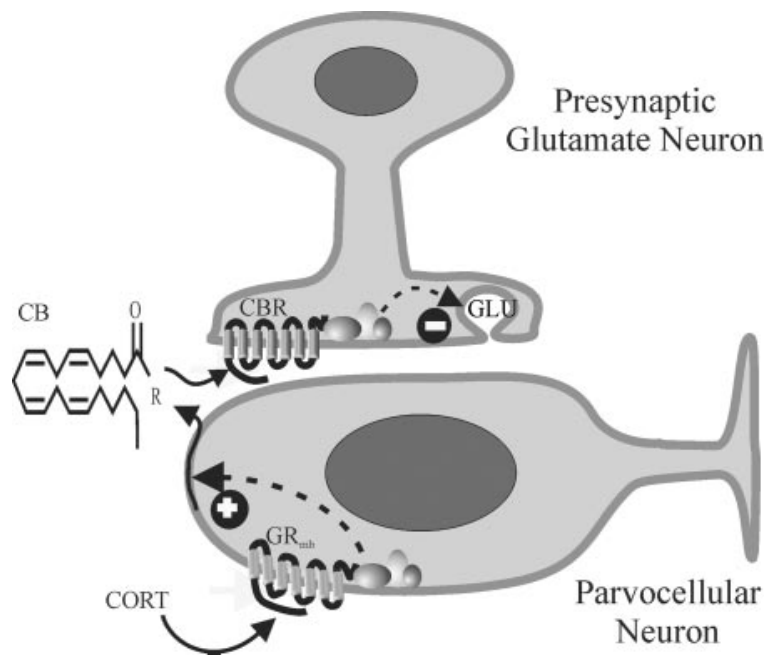

Figure 6. A model of the rapid glucocorticoid actions in PVN parvocellular neurons. The proposed mechanisms include glucocorticoid (CORT) binding to a G-protein-coupled glucocorticoid receptor $\left(\mathrm{GR}_{\mathrm{mb}}\right)$ and activation of an intracellular signaling pathway (dashed arrow) that leads to endocannabinoid synthesis (+). Endocannabinoid (CB) is released from the PVN neuron and binds to a G-protein-coupled $\mathrm{CB}_{1}$ cannabinoid receptor (CBR) on presynaptic glutamate terminals, activating a signaling cascade (dashed arrow) that leads to the inhibition of glutamate (GLU) release onto the PVN neuron-leading to decreased PVN neuronal activity and hormone secretion.

signaling mechanism and suggests that the membrane corticosteroid receptor in PVN parvocellular neurons is a G-proteincoupled receptor. Whether the kinase dependence of the response is associated with the postsynaptic G-protein signaling that leads to the release of endocannabinoid or with the presynaptic cannabinoid receptor signaling remains to be determined.
These findings are consistent with reports of G-protein and/or protein-kinase involvement in rapid corticosteroid actions in the brain, including radiolabeled corticosterone binding in amphibian neuronal membranes (Orchinik et al., 1992) and cortisol modulation of calcium currents in guinea pig CA1 pyramidal neurons (ffrench-Mullen, 1995).

\section{Release of a retrograde endocannabinoid messenger}

We found that the activation of a postsynaptic, G-proteindependent signaling mechanism led to the suppression of glutamate release, a presynaptic endpoint, thus implicating the involvement of a retrograde messenger. Inhibiting the retrograde messengers $\mathrm{NO}$ and $\mathrm{CO}$ failed to block the effect of glucocorticoid on mEPSC frequency or inhibition of cannabinoid receptors. Conversely, saturation with exogenous agonist or antagonist, respectively, abolished the effect of glucocorticoid on mEPSCs completely, suggesting that the retrograde messenger involved is an endocannabinoid. Our findings indicate that the glucocorticoid-induced endocannabinoid actions were mediated by presynaptic $\mathrm{CB}_{1}$ receptors, because they were blocked by $\mathrm{CB}_{1}$ receptor antagonists as well as by a $\mathrm{CB}_{2}$ receptor antagonist at a concentration effective at both $\mathrm{CB}_{2}$ and $\mathrm{CB}_{1}$ receptors but not at a concentration selective for $\mathrm{CB}_{2}$ receptors. This is consistent with the finding that $\mathrm{CB}_{1}$ receptors are the predominant receptors in the brain (Matsuda et al., 1990; Munro et al., 1993). Retrograde regulation of the synaptic release of glutamate and GABA by endocannabinoids is emerging as a widespread modulatory mechanism at synapses throughout the brain, including the hippocampus, cerebellum, striatum, and neocortex (Huang et al., 2001; Ohno-Shosaku et al., 2001). It is worth noting that the $\mathrm{CB}$ receptor antagonists we used are considered inverse agonists (Gifford et al., 1997; Ross et al., 1999), although neither had opposite actions on glutamate release, suggesting that they may not play an inverse agonistic role at the presynaptic receptors in the PVN at the concentrations used. Future studies will clarify the $\mathrm{CB}$ receptor mechanisms in the PVN.

Introduction of GDP- $\beta$-S into a single parvocellular neuron blocked the actions of glucocorticoids completely, suggesting that there was little or no spillover of endocannabinoids released by adjacent neurons onto the recorded neurons. This is consistent with a restricted secretion domain and limited spread of the endocannabinoids in the extracellular space. Unlike the gaseous retrograde messenger NO, which has been shown to spread to activate local GABA circuits in the PVN (Bains and Ferguson, 1997), retrogradely released endocannabinoids might be expected to have a restricted range of action because of their lipophilic nature (Kreitzer and Regehr, 2002).

It is interesting to note that the inhibitory actions on PVN neurosecretory cell activity of glucocorticoids and cannabinoids applied directly in the PVN in our experiments are opposite to the activational effects of systemic anandamide or $\Delta^{9}$ tetrahydrocannabinol on HPA hormone release (Murphy et al., 1998). However, the effects of systemic cannabinoids on HPA hormone secretion are accompanied by changes in PVN catecholamine levels (Murphy et al., 1990; Rodriguez de Fonseca et al., 1995), and are blocked completely by hypothalamic deafferentation (Puder et al., 1982). This suggests that the activational effects of cannabinoids occur upstream of the PVN, and that this cannabinoid-stimulated afferent excitation either is not glutamatergic or is glutamatergic and strong enough to override the $\mathrm{CB}_{1}$ receptor-mediated inhibition of glutamate release within the PVN. 


\section{Physiological significance}

Glucocorticoid feedback inhibition of the HPA axis appears to be mediated by steroid actions at different central targets, either indirectly via actions in the hippocampus or directly at the levels of the hypothalamus and pituitary (Dallman et al., 1987). Glucocorticoids have been reported to have direct inhibitory effects on the electrical activity of some parvocellular neurons of the PVN (Kasai and Yamashita, 1988; Saphier and Feldman, 1988), although the inhibitory mechanisms have not been determined and the identification of specific glucocorticoid-responsive PVN subpopulations has been inconclusive. We present evidence here for the inhibition by glucocorticoids of glutamate release onto parvocellular neurosecretory neurons of the PVN, including $\mathrm{CRH}$-expressing cells, which resulted in the suppression of excitatory inputs to these cells. This is the first demonstration, therefore, of a rapid inhibition of identified CRH neurons by corticosteroids, and provides a mechanism for the fast feedback inhibition of CRH release by glucocorticoids directly at the level of the hypothalamic CRH neurons.

In addition to the effect on CRH neurons, we found that glucocorticoids also exerted a similar inhibitory effect on glutamate release onto parvocellular TRH-expressing, OT-expressing, and VP-expressing neurons. These peptides, along with $\mathrm{CRH}$, are thought to play an anorexigenic role in the central control of feeding (Burlet et al., 1992; Rondeel et al., 1992). Glucocorticoids and endocannabinoids both have well established central orexigenic actions (Zakrzewska et al., 1999; Kirkham et al., 2002) such that the modulatory cross talk between glucocorticoids and endocannabinoids that leads to reduced excitation of PVN parvocellular neurons demonstrated here may also play a major role in the central control of feeding and energy balance.

The glucocorticoid-endocannabinoid interface via activation of a G-protein-dependent signaling pathway represents a novel mechanism of rapid steroid action in the brain. This endocannabinoid link between steroid hormonal and neuronal signaling expands the recently discovered role of endocannabinoids as retrograde modulators of synaptic function. The glucocorticoidinduced suppression of excitatory synaptic inputs to PVN parvocellular neurons is likely to play an important role in the acute negative feedback effect of glucocorticoids on HPA axis activity. Because the PVN is considered to be the main neuroendocrine and autonomic effector in the control of stress, energy balance, and homeostasis (Swanson and Sawchenko, 1980; Laugero, 2001), the modulatory cross talk between glucocorticoids and endocannabinoids in PVN parvocellular neurons provides a central mechanism for the well established orexigenic and homeostatic actions of both glucocorticoids and cannabinoids. This novel role of endocannabinoids as mediators of the negative feedback actions of glucocorticoids in the PVN provides new potential targets for the therapeutic treatment of stress and feeding disorders.

\section{References}

Auclair N, Otani S, Soubrie P, Crepel F (2000) Cannabinoids modulate synaptic strength and plasticity at glutamatergic synapses of rat prefrontal cortex pyramidal neurons. J Neurophysiol 83:3287-3293.

Avanzino GL, Ermirio R, Ruggeri P, Cogo CE (1987) Effects of corticosterone on neurons of reticular formation in rats. Am J Physiol 253:R25-R30.

Bains JS, Ferguson AV (1997) Nitric oxide regulates NMDA-driven GABAergic inputs to type I neurones of the rat paraventricular nucleus. J Physiol (Lond) 499:733-746.

Bredt DS, Hwang PM, Snyder SH (1990) Localization of nitric oxide synthase indicating a neural role for nitric oxide. Nature 347:768-770.
Burlet AJ, Jhanwar-Uniyal M, Chapleur-Chateau M, Burlet CR, Leibowitz SF (1992) Effect of food deprivation and refeeding on the concentration of vasopressin and oxytocin in discrete hypothalamic sites. Pharmacol Biochem Behav 43:897-905.

Dallman MF, Akana SF, Cascio CS, Darlington DN, Jacobson L, Levin N (1987) Regulation of ACTH secretion: variations on a theme of B. Recent Prog Horm Res 43:113-173.

de Kloet ER (2000) Stress in the brain. Eur J Pharmacol 405:187-198.

Evans SJ, Murray TF, Moore FL (2000) Partial purification and biochemical characterization of a membrane glucocorticoid receptor from an amphibian brain. J Steroid Biochem Mol Biol 72:209-221.

Falkenstein E, Tillmann HC, Christ M, Feuring M, Wehling M (2000) Multiple actions of steroid hormones-a focus on rapid, nongenomic effects. Pharmacol Rev 52:513-556.

ffrench-Mullen JM (1995) Cortisol inhibition of calcium currents in guinea pig hippocampal CA1 neurons via G-protein-coupled activation of protein kinase C. J Neurosci 15:903-911.

Gifford AN, Tang Y, Gatley SJ, Volkow ND, Lan R, Makriyannis A (1997) Effect of the cannabinoid receptor SPECT agent, AM 281, on hippocampal acetylcholine release from rat brain slices. Neurosci Lett 238:84-86.

Glasgow E, Kusano K, Chin H, Mezey E, Young III WS, Gainer H (1999) Single cell reverse transcription-polymerase chain reaction analysis of rat supraoptic magnocellular neurons: neuropeptide phenotypes and high voltage-gated calcium channel subtypes. Endocrinology 140:5391-5401.

Harrison RW, Balasubramanian K, Yeakley J, Fant M, Svec F, Fairfield S (1979) Heterogeneity of AtT-20 cell glucocorticoid binding sites: evidence for a membrane receptor. Adv Exp Med Biol 117:423-440.

Herman JP, Prewitt CM, Cullinan WE (1996) Neuronal circuit regulation of the hypothalamo-pituitary-adrenocortical stress axis. Crit Rev Neurobiol 10:371-394.

Hoffman NW, Tasker JG, Dudek FE (1991) Immunohistochemical differentiation of electrophysiologically defined neuronal populations in the region of the rat hypothalamic paraventricular nucleus. J Comp Neurol 307:405-416.

Hua SY, Chen YZ (1989) Membrane receptor-mediated electrophysiological effects of glucocorticoid on mammalian neurons. Endocrinology 124:687-691.

Huang CC, Lo SW, Hsu KS (2001) Presynaptic mechanisms underlying cannabinoid inhibition of excitatory synaptic transmission in rat striatal neurons. J Physiol (Lond) 532:731-748.

Kasai M, Yamashita H (1988) Inhibition by cortisol of neurons in the paraventricular nucleus of the hypothalamus in adrenalectomized rats: an in vitro study. Neurosci Lett 91:59-64.

Keller-Wood ME, Dallman MF (1984) Corticosteroid inhibition of ACTH secretion. Endocr Rev 5:1-24.

Kirkham TC, Williams CM, Fezza F, Di Marzo V (2002) Endocannabinoid levels in rat limbic forebrain and hypothalamus in relation to fasting, feeding and satiation: stimulation of eating by 2-arachidonoyl glycerol. Br J Pharmacol 136:550-557.

Kreitzer AC, Regehr WG (2002) Retrograde signaling by endocannabinoids. Curr Opin Neurobiol 12:324-330.

Laugero KD (2001) A new perspective on glucocorticoid feedback: relation to stress, carbohydrate feeding and feeling better. J Neuroendocrinol 13:827-835.

Luther JA, Halmos KC, Tasker JG (2000) A slow transient potassium current expressed in a subset of neurosecretory neurons of the hypothalamic paraventricular nucleus. J Neurophysiol 84:1814-1825.

Luther JA, Daftary SS, Boudaba C, Gould GC, Halmos KC, Tasker JG (2002) Neurosecretory and non-neurosecretory parvocellular neurons of the hypothalamic paraventricular nucleus express distinct electrophysiological properties. J Neuroendocrinol 14:929-932.

Matsuda LA, Lolait SJ, Brownstein MJ, Young AC, Bonner TI (1990) Structure of a cannabinoid receptor and functional expression of the cloned cDNA. Nature 346:561-564.

Munro S, Thomas KL, Abu-Shaar M (1993) Molecular characterization of a peripheral receptor for cannabinoids. Nature 365:61-65.

Murphy LL, Steger RW, Smith MS, Bartke A (1990) Effects of delta-9tetrahydrocannabinol, cannabinol and cannabidiol, alone and in combinations, on luteinizing hormone and prolactin release and on hypothalamic neurotransmitters in the male rat. Neuroendocrinology 52:316-321.

Murphy LL, Munoz RM, Adrian BA, Villanua MA (1998) Function of can- 
nabinoid receptors in the neuroendocrine regulation of hormone secretion. Neurobiol Dis 5:432-446.

Ohno-Shosaku T, Maejima T, Kano M (2001) Endogenous cannabinoids mediate retrograde signals from depolarized postsynaptic neurons to presynaptic terminals. Neuron 29:729-738.

Orchinik M, Murray TF, Moore FL (1991) A corticosteroid receptor in neuronal membranes. Science 252:1848-1851.

Orchinik M, Murray TF, Franklin PH, Moore FL (1992) Guanyl nucleotides modulate binding to steroid receptors in neuronal membranes. Proc Natl Acad Sci USA 89:3830-3834.

Puder M, Weidenfeld J, Chowers I, Nir I, Conforti N, Siegel RA (1982) Corticotrophin and corticosterone secretion following delta 1-tetrahydrocannabinol in intact and in hypothalamic deafferentated male rats. Exp Brain Res 46:85-88.

Rodriguez de Fonseca FR, Villanua MA, Munoz RM, Martin-Clark O, Navarro M (1995) Differential effects of chronic treatment with either dopamine $\mathrm{D} 1$ or $\mathrm{D} 2$ receptor agonists on the acute neuroendocrine actions of the highly potent synthetic cannabinoid HU-210 in male rats. Neuroendocrinology 61:714-721.

Rondeel JM, Heide R, de Greef WJ, van Toor H, van Haasteren GA, Klootwijk W, Visser TJ (1992) Effect of starvation and subsequent refeeding on thyroid function and release of hypothalamic thyrotropin-releasing hormone. Neuroendocrinology 56:348-353.

Ross RA, Brockie HC, Stevenson LA, Murphy VL, Templeton F, Makriyannis A, Pertwee RG (1999) Agonist-inverse agonist characterization at CB1 and CB2 cannabinoid receptors of L759633, L759656, and AM630. Br J Pharmacol 126:665-672.
Saphier D, Feldman S (1988) Iontophoretic application of glucocorticoids inhibits identified neurones in the rat paraventricular nucleus. Brain Res 453:183-190.

Shen M, Piser TM, Seybold VS, Thayer SA (1996) Cannabinoid receptor agonists inhibit glutamatergic synaptic transmission in rat hippocampal cultures. J Neurosci 16:4322-4334.

Surmeier DJ, Song WJ, Yan Z (1996) Coordinated expression of dopamine receptors in neostriatal medium spiny neurons. J Neurosci 16:6579-6591.

Suyemitsu T, Terayama H (1975) Specific binding sites for natural glucocorticoids in plasma membranes of rat liver. Endocrinology 96:1499-1508.

Swanson LW, Sawchenko PE (1980) Paraventricular nucleus: a site for the integration of neuroendocrine and autonomic mechanisms. Neuroendocrinology 31:410-417.

Tasker JG, Dudek FE (1991) Electrophysiological properties of neurones in the region of the paraventricular nucleus in slices of rat hypothalamus. J Physiol (Lond) 434:271-293.

Wilson RI, Nicoll RA (2001) Endogenous cannabinoids mediate retrograde signalling at hippocampal synapses. Nature 410:588-592.

Wilson RI, Kunos G, Nicoll RA (2001) Presynaptic specificity of endocannabinoid signaling in the hippocampus. Neuron 31:453-462.

Zakrzewska KE, Cusin I, Stricker-Krongrad A, Boss O, Ricquier D, Jeanrenaud B, Rohner-Jeanrenaud F (1999) Induction of obesity and hyperleptinemia by central glucocorticoid infusion in the rat. Diabetes 48:365-370. 